\title{
LETTER
}

\section{Hyperlactatemia in critical illness and cardiac surgery}

\author{
Enda D O'Connor ${ }^{* 1}$ and John F Fraserer-4 \\ See related research by Nichol et al., http://ccforum.com/content/14/1/R25
}

We read with interest the article by Nichol and colleagues [1] in a recent issue of Critical Care. Their study of more than 7,000 medical and surgical patients supports the claim that an admission plasma lactate level in the upper normal range is associated with increased mortality. However, we are concerned about the lack of data regarding patient baseline characteristics. Specifically, although 3,166 and 1,614 patients had diagnoses of 'surgery' and 'cardiac/vascular', respectively, it is likely, but not stated, that numerous patients were admitted following cardiac surgery. This is of great importance as changes in lactate in this patient group are not homogenous in nature.

In post-cardiac surgery patients, early hyperlactatemia and late hyperlactatemia (LHL) differ in both risk profile and physiological rationale. Early hyperlactatemia (on intensive care unit arrival) is associated with adverse outcome. This association is not seen in the $10 \%$ to $20 \%$ of patients who develop LHL (pooled odds ratio [OR] of death with LHL in two published trials 1.39, 95\% confidence interval [CI] 0.28 to 7.04) [2-4]. Moreover, in our recent single-center review of prospectively collated data from 529 post-cardiac surgical patients in a tertiary Australian cardiac surgical intensive care unit, 25\% developed LHL $(>2.5 \mathrm{mmol} / \mathrm{L})$. When compared with patients with a normal lactate profile, patients with LHL showed no increase in hospital mortality (OR 0.57, 95\% CI 0.07 to 5.05) (unpublished data).

Therefore, we believe that inclusion of such patients in studies of lactate in critical illness should be avoided and, as in the study by Nichol and colleagues, may actually weaken any association demonstrated between lactate levels and hospital mortality.

\section{Authors' response}

Alistair D Nichol, Michael Bailey and Rinaldo Bellomo

We thank O'Connor and Fraser for their comments, which suggest a differing association between early and late hyperlactatemia and mortality in post-operative cardiac surgery patients and that the inclusion of this cohort in our 'cardiac/vascular' group may have weakened the association between lactate and mortality in our study.

They are correct in assuming that a significant number of patients from the 'cardiac/vascular' group were postoperative cardiac patients, as three of the four intensive care units in our study support busy cardiothoracic services. Unfortunately, the coding of our database prevents us from identifying these patients in more detail. However, we were able to separate and examine the

*Correspondence: endamed@yahoo.com.au

'Locum Consultant Intensive Care, The Prince Charles Hospital, Rode Road,

Brisbane, QLD 4032, Australia

Full list of author information is available at the end of the article cardiac/vascular group, the surgical group, and the cardiac/vascular patients who underwent surgery. In the cardiac/vascular surgical group, the risk of death was increased with hyperlactatemia compared with all of the other groups (Table 1). In addition, the risk of death determined by maximal and time-weighted lactate (more strongly reflecting post-admission lactate levels) was greater in the cardiac/vascular surgical group compared with the other groups (Table 1).

These findings demonstrate that early (admission) and late (post-admission) hyperlactatemia are both strongly associated with mortality in cardiac/vascular surgical patients (of whom a significant number were postoperative cardiac patients). This would suggest that the inclusion of cardiac surgical patients did not weaken the association with mortality; it actually strengthened the overall association. These findings demand more study of lactate in the cardiac surgical cohort, and we eagerly await the publication of the results alluded to by O'Connor and Fraser. 
Table 1. Odds ratios of mortality for a 1-unit increase in lactate, adjusting for gender, age, APACHE II, mechanical ventilation, and diagnosis type considering the full dataset and three subgroups

\begin{tabular}{|c|c|c|c|c|c|}
\hline Lactate variable & Number & Odds ratio & Lower $95 \% \mathrm{Cl}$ & Upper $95 \% \mathrm{Cl}$ & Group \\
\hline $\mathrm{LaC}_{\mathrm{ADM}}$ & 7,155 & 1.12 & 1.09 & 1.16 & Full Group \\
\hline $\mathrm{LaC}_{\mathrm{ADM}}$ & 3,166 & 1.18 & 1.11 & 1.26 & Surg Only \\
\hline $\operatorname{Lac}_{\mathrm{ADM}}$ & 1,614 & 1.13 & 1.07 & 1.21 & Card/Nasc Only \\
\hline $\mathrm{LaC}_{\mathrm{ADM}}$ & 743 & 1.35 & 1.14 & 1.60 & Card/Vasc \& Surg Only \\
\hline $\mathrm{LaC}_{\operatorname{MAX}}$ & 7,155 & 1.15 & 1.12 & 1.17 & Full Group \\
\hline $\operatorname{Lac}_{\text {MAX }}$ & 3,166 & 1.14 & 1.10 & 1.19 & Surg Only \\
\hline $\mathrm{LaC}_{\operatorname{MAX}}$ & 1,614 & 1.11 & 1.06 & 1.15 & Card/Nasc Only \\
\hline $\mathrm{LaC}_{\operatorname{MAX}}$ & 743 & 1.18 & 1.09 & 1.27 & Card/Vasc \& Surg Only \\
\hline $\mathrm{Lac}_{\mathrm{TW}}$ & 7,155 & 2.08 & 1.90 & 2.27 & Full Group \\
\hline $\mathrm{Lac}_{\mathrm{TW}}$ & 3,166 & 2.17 & 1.83 & 2.57 & Surg Only \\
\hline $\mathrm{Lac}_{\mathrm{TW}}$ & 1,614 & 2.37 & 1.92 & 2.93 & Card/Nasc Only \\
\hline $\mathrm{Lac}_{\mathrm{TW}}$ & 743 & 4.16 & 2.45 & 7.07 & Card/Vasc \& Surg Only \\
\hline
\end{tabular}

APACHE II, Acute Physiology and Chronic Health Evaluation II; Card/Vasc Only, only cardiac/vascular patients; Card/Vasc \& Surg Only, only cardiac/vascular surgery

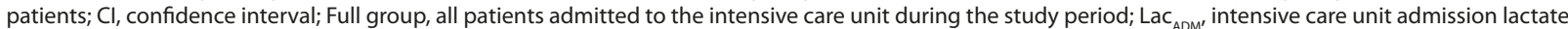
concentration; $\mathrm{LaC}_{\mathrm{MAx}^{\prime}}$ maximal lactate concentration; $\mathrm{LaC}_{\mathrm{TW}^{\prime}}$ time-weighted lactate concentration; Surg Only, only surgery patients.

\section{Abbreviations}

$\mathrm{Cl}$, confidence interval; LHL, late hyperlactatemia; OR, odds ratio.

\section{Competing interests}

The authors declare that they have no competing interests.

\section{Author details}

'Locum Consultant Intensive Care, The Prince Charles Hospital, Rode Road, Brisbane, QLD 4032, Australia. ${ }^{2}$ Critical Care Research Group, The Prince Charles Hospital, Rode Road, Brisbane, QLD 4032, Australia. ${ }^{3}$ Critical Care and Anaesthesia, School of Medicine, University of Queensland, Georges Street, Brisbane, QLD 4072, Australia. ${ }^{4}$ School of Engineering Systems, Faculty of Built Environment and Engineering, Queensland University of Technology, Brisbane, QLD 4001, Australia.

Published: 3 June 2010

\section{References}

1. Nichol AD, Egi M, Pettila V, Bellomo R, French C, Hart G, Davies A, Stachowski E, Reade MC, Bailey M, Cooper DJ: Relative hyperlactatemia and hospital mortality in critically ill patients: a retrospective multi-centre study. Crit Care 2010, 14:R25.

2. Totaro RJ, Raper RF: Epinephrine-induced lactic acidosis following cardiopulmonary bypass. Crit Care Med 1997, 25:1693-1699.

3. Raper RF, Cameron G, Walker D, Bowey CJ: Type B lactic acidosis following cardiopulmonary bypass. Crit Care Med 1997, 25:46-51.

4. Maillet JM, Le Besnerais P, Cantoni M, Nataf P, Ruffenach A, Lessana A, Brodaty $D$ : Frequency, risk factors, and outcome of hyperlactatemia after cardiac surgery. Chest 2003, 12:1361-1366.

\section{doi:10.1186/cc9017}

Cite this article as: O'Connor ED, Fraser JF: Hyperlactatemia in critical illness and cardiac surgery. Critical Care 2010, 14:421. 